\title{
Crítica de mídia a partir de experiências em web arte ${ }^{1}$
}

\section{Media criticism through experiences in web art}

Andrea Limberto ${ }^{2}$ realizado em 21 e 22 de setembro de 2017 na Universidade Federal de Santa Catarina (UFSC). Apresentação disponível em: <https://bit.ly/2qDXQdx>. Acesso em: 17 abr. 2018. 


\section{Resumo}

Tomando por hipótese que um estudo da crítica de mídia pode ser feito por intermédio da observação dos processos de inovação formal sobre a linguagem dos meios, recuperamos experiências em web arte para uma investigação sobre como o trabalho com recursos digitais tem informado criticamente os circuitos de produção midiática. Adotamos, como estudo de caso, os trabalhos de Lucas Bambozzi e Fábio Fon tanto pelo desafio que apresentam (um retrabalho com elementos do referido circuito midiático) como pelo acúmulo das funções autoral, curatorial, realizadora e analista, colocando em debate também os lugares autorizados dos quais parte a crítica. Propomos identificar um tipo específico de crítica nascida de um processo de apropriação não autoral a partir da usabilidade formal e mutabilidade dos formatos. Ela lida com uma maior aproximação entre as linguagens do jornalismo, do entretenimento e da arte. Embora essa conjunção seja estudada hoje a partir de diferentes abordagens teóricas, ela identifica um novo momento também para a teoria crítica.

\section{Palavras-chave}

Crítica de mídia, meios digitais, web arte, Lucas Bambozzi, Fábio Fon.

\section{Abstract}

Considering that media criticism can be approached through the observation of formal media innovation processes, this article recovers web art experiences for an investigation on how digital resources critically impact the circuits of media production. It focuses on a case study of the artistic and theoretical works of Lucas Bambozzi and Fábio Fon, they represent that research challenge on the level of what they present (a reenactment of elements present in the media circuit) and also on the level of their roles as authors, curators, makers and analysts, defying the places from where media criticism is originated. We identify a type of media criticism born (almost) involuntarily which is a result from a process of non-authorial appropriation using formal usability and transformation of formats. Journalism, entertainment and art languages converge, both in content and in the form that is presented. This convergence has been studied from different theoretical perspectives, however, it also points to a new moment of critical theory.

\section{Keywords}

Media criticism, digital media, web art, Lucas Bambozzi, Fábio Fon. 
Tomando por hipótese de base que um estudo da crítica de mídia pode ser feito pela observação dos processos de inovação formal sobre a linguagem dos meios, propomos uma recuperação de experiências em web arte como ponto de partida para uma investigação sobre como o trabalho com recursos digitais tem informado criticamente os circuitos de produção midiática. Trata-se de observar o ponto em que o exercício midiático se coloca no limite de padrões estéticos e sociais estabelecidos e, nessa região de fronteira, se oferece como material para o estudo da crítica de mídia na forma de um efeito crítico. Tal efeito se relaciona com um momento que é ao mesmo tempo histórico, formal, estético e de produção de sentido vinculado a uma experiência coletiva e popular. Rosana Soares e Gislene Silva (2016, p. 12) apontam essa dinâmica de emergência crítica, elencando uma das entradas para o estudo da crítica de mídia a partir do próprio fazer midiático

nas experiências metacríticas, em termos de conteúdo e forma, das inovações estéticas e estilísticas veiculadas na própria mídia, que, ao propor um novo formato ou gênero, empreendem uma crítica àquilo estabelecido como padrão, realizando-a não como uma análise sobre a mídia, mas no próprio fazer midiático.

Não se pode esperar que as inovações estéticas e estilísticas tenham correspondência imediata ao belo no momento de sua emergência, pois apontam para elementos fora da quadratura desejada e, em certo sentido, deve-se esperar a falta de acolhida do resultado. "A beleza, qualquer que seja seu significado, possui tal poder de atração sobre os seres humanos que ela se legitima por si mesma, dispensando qualquer apologia. A arte já não tem a mesma sorte" (SHUSTERMAN, 1998, p. 59). Se não estamos no âmbito de uma apologia dos objetos midiáticos, não podemos parar no apontamento de uma alogia, como algo que não se pode explicar com uma lógica que nos envolve, e no ponto da inovação total, como se insurgência crítica partisse de um lugar de total novidade. O que trabalharemos com a web arte na relação com a mídia é justamente o oposto desse movimento de construção de novidade, de inovação formal: um trabalho com a replicação e 
com a reprodução. O desgaste com a reprodutibilidade técnica gera, de algum modo, uma variação de sentido e um deslocamento incessante.

A própria noção de autenticidade não tem sentido para uma reprodução, seja técnica ou não. Mas, diante da reprodução feita pela mão do homem e, em princípio, considerada uma falsificação, o original mantém a plena autoridade; não ocorre o mesmo no que concerne à reprodução técnica. E isto por dois motivos. De um lado, a reprodução técnica está mais independente do original. [...] Ao mesmo tempo, a técnica pode levar a reprodução de situações, onde o próprio original jamais seria encontrado (BENJAMIN, 1975, p. 13).

Com Walter Benjamin, revisamos os termos de nossa proposta: a web arte só poderia cunhar-se como objeto artístico levando a reprodução de seus elementos originais a níveis em que o próprio original já não está. Ele não está porque foi recortado, deslocado, justaposto com outros pedaços desfigurados de originais que se recompõem num todo não apontando mais para o sentido artístico. Defendemos aqui que sua mira é a mídia e o movimento de reprodução devolve em sentido para uma crítica de mídia. A partir de gradual familiarização com os efeitos obtidos naquilo que podemos chamar de operação artística, com sua incorporação nas dinâmicas midiáticas a partir das estruturas que movimenta, podemos dizer também que o efeito crítico não é localizado e nem permanente, ou seja, está além da obra artístico-midiática e não ficará vinculado a ela, a não ser historicamente, ao movimento disjuntivo que a motivou. Ela não pode ser entendida, assim, como uma obra crítica em si de maneira separada de um determinado circuito de circulação artístico-midiática,

não pode, portanto, ser julgada em si, isoladamente de sua forma de apropriação. O resultado é que as obras de arte são menos culpadas pelo seu poder perverso do que pela sua impotência de determinar seu próprio significado e uso (SHUSTERMAN, 1998, p. 63).

Tendo em vista o presente exercício de análise da crítica midiática na fronteira entre a mídia e a arte, adotamos como estudo de caso os trabalhos artísticos e teóricos de Lucas Bambozzi e Fábio Fon por representarem o desafio 
teórico que pretendemos no que apresentam: um retrabalho com elementos do referido circuito midiático, suas obras recorrem a objetos tecnológicos retirados de seu contexto trivial de uso e contrastados com a incoerência de sua valorização na cultura. Operam também o jogo entre visibilidades e invisibilidades, ponto em que as dinâmicas de um circuito tecnológico e de circulação midiática se encontram e, ao mesmo tempo, tentam fazer ver os locais em que essa mesma dinâmica ofusca forças sociais e comunicativas prontas a emergir.

Uma questão que justifica a escolha pelo estudo de caso mencionado é a aglutinação dos modos de atuação artística, crítica e teórica na figura dos próprios realizadores. Acreditamos que ela seja sintomática dos processos de produção avalizados pelos meios digitais e pelo exercício autoral favorecido. Quanto ao exame da crítica, questionamos justamente a possibilidade de esse ser o espaço da arte e da mídia a ser utilizado, especialmente pela voz dos artistas em questão, e assumimos a relativa independência formal dos trabalhos para que se possa fazer ver o ciclo crítico que as obras promovem. Pelo acúmulo das funções autoral, curatorial, realizadora e analista em suas figuras, dessa forma colocam em debate os lugares autorizados dos quais parte a crítica.

Combinando especialmente esses dois pontos desafiadores, propomos identificar um tipo específico de crítica nascida (quase) involuntariamente e resultante de um processo de apropriação não autoral a partir da usabilidade de formas e mutabilidade dos formatos. Ela lida com uma maior aproximação entre as linguagens do jornalismo, dos meios direcionados ao entretenimento e da arte, que se revelam tanto no conteúdo quanto na forma do que é apresentado. Embora essa conjunção seja estudada hoje a partir de diferentes abordagens teóricas, ela identifica um novo momento também para a teoria crítica. Nosso objetivo não é avaliar a potência crítica das experiências, mas captar aquilo que, ao se anunciar no lugar da experimentação midiática, abre um espaço de cisão e permite identificar o que culturalmente poderia ser objeto da crítica. No primeiro nível, há um questionamento da materialidade dos meios, o esmaecimento da dualidade entre o verdadeiro e o falso, além de um trabalho entre visibilidades e invisibilidades. 


\section{Experiências em web arte podem funcionar para uma crítica de mídia}

Web arte é um termo que tem sido usado inicialmente para a arte feita usando os recursos tecnológicos e disponibilizada on-line ou exposta em ambientes preparados. Trata-se de uma definição instável na medida em que a presença da rede se oferece fora dos espaços de computadores pessoais e pode habitar os ambientes fora da casa e de encontro coletivo, ainda que com a presença da mediação pela tela. Consideramos que é importante pontuar a relação com os recursos tecnológicos, a programação e a utilização de múltiplas linguagens, como a do texto e a do audiovisual. Gilbertto Prado (2003) considera a distinção entre rede telemática e a arte desenvolvida para a web diferenciando a memória da produção realizada, no primeiro caso durando o tempo do estabelecimento da rede e, no segundo, sendo mantida na internet, em sua capacidade de funcionar como banco de dados.

A relação que se estabelece, como nos trabalhos que veremos, é mais apropriadamente entre arte e tecnologia. Os recursos principalmente associados a esse tipo de arte são os da visibilidade pelas telas (de computador e de vídeo, aproximando-se da videoarte) e da interatividade (por cliques ou toques permitindo a abertura de níveis de conteúdo).

Os criadores que trabalham hoje com esses meios crêem estar diante de novas possibilidades e de transformações consideráveis, ou seja, diante de novos desafios. Entretanto, o interesse principal é de trazer uma visão sensível e crítica com a ajuda dessas novas possibilidades e ao mesmo tempo favorecer e estimular a circulação do imaginário social e coletivo. Desta forma, os artistas podem ajudar a explorar o espaço tecnológico e suas contradições (PRADO, 2003, p. 24).

Nossa hipótese não é tratar das mídias digitais ou da web arte como algo novo, mas indicar como suas possibilidades formais favorecem o trabalho de justaposição de objetos e produzem um tipo de crítica específico que é, ao mesmo tempo, comentário e condensação de referências sobre as matérias condensadas. Se assumimos que a crítica se faz também nesse tipo de atividade, podemos argumentar que há um aumento na possibilidade de trabalho crítico, embora nem 
todo o trabalho artístico ou de web arte o seja. Para o fazer crítico, além do trabalho com as referências de base é necessária também uma virada interpretativa que destoa e desloca sentidos. Nosso ponto de partida para entender a web arte é o que ela recebe como herança a partir das artes moderna e contemporânea, da publicidade e da propaganda, como áreas de trabalho com códigos e estéticas específicos que acabam por se tocar na produção de conteúdo para os meios e na tentativa de apropriação pela arte digital. Acreditamos que esse encontro é potencialmente crítico.

Mas de que tipo de crítica de mídia estamos falando? Trata-se de uma tomada específica que privilegia o encontro formal da produção midiática e entende que o valor de tais produções está determinado pela caracterização de uma função, que é tanto estética quanto política e social. Esse comentário específico sobre a usabilidade do meio digital tem a contribuir para o debate sobre crítica e mídia no ponto em que uma diferença na abordagem dos processos comunicativos, no caso digitais, provocam alteração no pensar sobre eles mesmos.

A escrita é, por natureza, ao mesmo tempo descritiva, poética e metafísica; em outras palavras, ela descreve um objeto referencial, evoca as sensações provocadas por esse objeto em uma sensibilidade e subsume esse objeto em um conceito, resgata sua validade universal, seu sentido.

Essas três funções se reencontram na prática da crítica de arte. Esta deve designar o objeto de seu discurso dentro de sua autonomia: um quadro, uma instalação, a imagem de um corpo, a fotografia de um nevoeiro na contraluz, etc (LEENHARDT, 2007, p. 20).

No caso dos meios digitais, para além da questão da usabilidade formal, estamos tratando de uma aposta na disseminação de uma lógica comum do digital que pode ser considerada de domínio e sentido comuns e assim desafiada em sua tomada pública da mesma forma, ou seja, a crítica aos meios digitais e ao uso da tecnologia consegue atingir um nível coletivo. Consideramos, assim, que a circulação extensiva das produções midiáticas, como fenômeno associado à possibilidade técnica de sua reprodução, afeta a obra e sua interpretação. 
A aderência entre obra e o espaço estendido que ocupa na forma de comentários, desdobramentos, retomadas e remixagens deve ser considerada como parte de sua fortuna crítica. "O fenômeno da crítica cinematográfica construída a partir de redes hipertextuais desfoca a racionalidade específica da crítica em seu formato tradicional para uma experiência em espaço acústico" (FREITAS; PEREIRA, 2013).

Devemos considerar aqui a importante questão da divisão ou, se quisermos dizer, do hiato digital, a falta de acesso e de literacia tecnológica ainda premente hoje, ao mesmo tempo em que apostamos que uma lógica de utilização tecnológica num lugar hegemônico tem seus efeitos para além da possibilidade de posse de seus aparelhos em cada ponto do processo, com cada indivíduo e suas maneiras de uso e apropriação. Pensamos que a crítica ao meio digital não se restringe a suas produções, ou seja, não é uma crítica de nicho, mas implica o sentido de um discurso tecnológico e científico que está hoje no centro do debate social, ainda que considerando o referido hiato. A crítica que passa pela web arte é justamente o oposto: ela reflete sobre as tomadas dos processos tecnológicos nas produções midiáticas e nas formas de viver, de maneira mais ampla. Como metáfora da tecnologia e de um discurso cientificista para a compreensão do mundo, as produções midiáticas digitais remetem à possibilidade de fazer uso do conhecimento e da habilidade técnicos de quem faz. Sua metáfora artística envolve, então, um sujeito do fazer tecnológico que se identifica com as produções que vê materializadas e se identifica também com as retomadas artísticas que se possa fazer delas, contemplado também como sujeito hábil desse fazer. O desafio da web arte não é tanto de recursos técnicos, em muitos casos, mas de compartilhar junções inesperadas a partir do domínio de uso tecnológico comum.

Para isso, a imaginação crítica toma emprestada da linguagem sua função "poética", principalmente sua estrutura metafórica. No discurso crítico, o objeto de arte é sempre, além daquilo que parecer ser, descrito através do modo analógico do "como". Ele é isto e outra coisa ao mesmo tempo (LEENHARDT, 2007, p. 21). 


\section{Que mídias digitais estamos implicando?}

É importante, neste ponto, identificarmos de que mídias digitais estamos tratando. Quando pensamos nelas não estamos restringindo o debate às redes sociais, ainda que saibamos que elas são a porta de entrada para o interesse pela utilização tecnológica e impulso para sua literacia. Também não o estamos limitando à esfera das possibilidades da internet, mas entendemos que, para além da ideia de que haja uma rede de computadores, há uma produção de sentido em torno da apropriação dos objetos tecnológicos. Assim, a web arte se dispõe a trabalhar como crítica a essa rede a partir do mecanismo de chamar a atenção para a formação de outra rede, essa social, política e ideológica, envolvendo as possibilidades de uso dos meios digitais: desvia as possibilidades em curso, tenta deslocar suas posições nessa teia e sonha produzir novos padrões tecnopoéticos de utilização.

Estamos pensando essas mídias como ponta de um discurso tecnológicocientífico que se diz digital na forma de uso, em contraponto ao que seria uma cultura do analógico, embora muitos defendam que não falemos mais dos mecanismos do digital, nomeado dessa forma após a incorporação do seu uso para os processos de comunicação. Trata-se de uma forma de produção que envolve o reforço de características específicas, como a fragmentaridade e a reprodutibilidade técnica. Existem já hoje muitas camadas de especificidade se sobrepondo até que se desponte em redes e aplicativos que são amigáveis aos usuários e, nesse sentido pontual, procurem o máximo de inclusão, como as redes sociais. Num movimento de retorno, essa cooptação coletiva acaba por se envolver também coletivamente em algo que estamos chamando como a lógica dos meios digitais. Nossa proposta aqui é que, se há algo de coletivo nessa vivência, há espaço para uma arte e uma mídia que são críticas. Ao pensar as mídias digitais, temos uma dupla entrada para a noção de coletividade, a primeira delas sendo a que descrevíamos como comunidade de compartilhamento das produções e da habilidade tecnológica e a segunda, mais sutil, um consenso interpretativo sobre as produções midiáticas desse tipo. Entendemos que tal interpretação esteja no domínio da crítica e que, 
ao habilitar usuários, em certa medida os polos de interpretação são ampliados e a atividade crítica deslocada.

Se os públicos são relativamente cegos ao que se passa no quadro, é porque sua experiência cotidiana não Ihes dá senão raramente a oportunidade de prestar atenção nas diferenças em que reside todo o interesse do quadro. Aprendemos a ler e a escrever, não a olhar (LEENHARDT, p. 20).

Se pensamos que a crítica se baseia num necessário movimento de retorno, aí está o que estamos pleiteando em relação aos meios digitais. Ele se dá a partir de uma repetição técnica e estética incessante que provoca distorção e agregamento de novos sentidos, como restos, como "a mais" de um desenvolvimentismo e de um progresso tecnológico. Os artistas usam seus olhos; muitas vezes conseguem acertar nos objetos desse "a mais", mas muitas vezes não.

Cabe dizer, então, que se trata não de uma lógica da crítica que se baseia na aparição do novo, mas do desgaste pela repetição. Quando tratamos dessa repetição nos colocamos não no campo da arte, nem da crítica da arte, mas no limiar dos procedimentos midiáticos. E dessa forma nos interessam como desmistificação da aura artística e queda num ambiente mais duro e estéril para que o sentido seja dado preferencialmente fora de si, na experiência do expectador, e não por ser ele o autor ou coautor da obra de arte, mas no compartilhamento e no pertencimento a uma mesma rede de circuitos de significantes e significados. Defendemos, assim, a reposição possível de todas as obras de arte e da arte em geral para o campo do domínio popular. Este é um público revitalizado no uso das mídias, inclusive em sua alçada técnica, e na possibilidade de criação e expressão, embora devamos sempre admitir o contraponto da existência de um campo cada vez mais elitizado e especializado (contra o que os códigos de acesso aberto também se colocam). Não está longe, então, associarmos as tentativas de criação de arte usando recursos tecnológicos e um discurso politizado em relação ao uso e ao acesso dos mesmos materiais e conteúdos.

Assim, é importante reforçar que não se trata de retomar o debate sobre interatividades possíveis nos meios digitais para poder falar de crítica de mídia, 
já que ela não está em permitir a entrada do outro (o espectador) no universo artístico criado para compartilhar o que um doa e oferece de caminhos. Trata-se, acima disso, de roubar algo comum, que é também desse outro, e negociar com ele o estatuto de arte. A crítica como educação do olhar para as artes perde sentido para dar vazão à crítica como reconhecimento pessoal e social de sentidos. E, dessa forma, a obra que computamos seca e estéril acontece ou não (quase por acaso) fora do controle educacional pedagógico e orientado (que muitas vezes é o caso dos espaços de museus e arquivos).

O aspecto da pulverização e do espraiamento tecnológico contribui para que a arte esteja presente fora dos ambientes controlados, disponível para quem tiver um ponto de acesso e, dessa forma, desafia a própria noção do que é arte. Se esta é composta também pelos espaços que selecionam e nomeiam os objetos ali expostos (crítica presente de maneira sintomática nas obras de arte moderna e no desafio aos tradicionais salões artísticos), o desapegar desses espaços é uma crítica circunstancial do valor dos objetos artísticos e, quando mais, de sua própria definição. O termo web arte vem para ocupar o espaço dessa delimitação apelando aos recursos técnicos utilizados em sua produção, mas sem se fixar ainda em novas institucionalidades possíveis do campo artístico: quais são os materiais utilizados, que técnicas são empregadas, que circuitos artísticos percorrem?

O que podemos dizer de importante para nosso debate é que a indiferenciação de alguma forma é gerada entre os circuitos da arte e o circuito midiático - que, como por colapso sintomático, disputam uma delimitação de objeto. Nesse ponto, acreditamos que tratar de críticas de arte e de mídia a um só tempo é importante, pois é o lugar no qual a crítica encontra o desmonte de seu objeto de juízo, a inaplicabilidade de suas teorias e os espaços de validação de sua exposição e julgamento. Temos a abertura de objetos a quem somos apresentados caso a caso, no momento de sua emergência, que demandam a revisão das chaves existentes de análise, desafiam a estabilidade das articulações que os procura captar e questionam os espaços pelos quais a crítica é emitida (por repetir a mesma base e ser de estabelecimento coletivo). 


\section{Trabalhos artísticos e teóricos de Lucas Bambozzi e Fábio Fon}

Lucas Bambozzi e Fábio Fon são dois artistas e pesquisadores brasileiros com relativa proeminência, ambos trabalhando os caminhos da hipermídia, web arte e visualidades nas mídias digitais. Fábio Oliveira Nunes (Fábio Fon) publicou Web arte no Brasil (2003) e CTRL+ART+DEL: distúrbios em arte e tecnologia (2010), enquanto dos trabalhos de Bambozzi destacamos youTag (2009) e sua dissertação Public spaces and pervasive systems: a critical practice ("Espaços públicos e sistemas pervasivos: uma prática crítica", 2006). São uma constante em seus trabalhos recentes as questões relacionadas ao conceito de espaço informacional e as particularidades da arte produzida a partir das mobilidades e imobilidades do contexto urbano. Podemos dizer que suas obras posicionam elementos criticamente e isso gera não a crítica em si, mas questionamentos críticos.
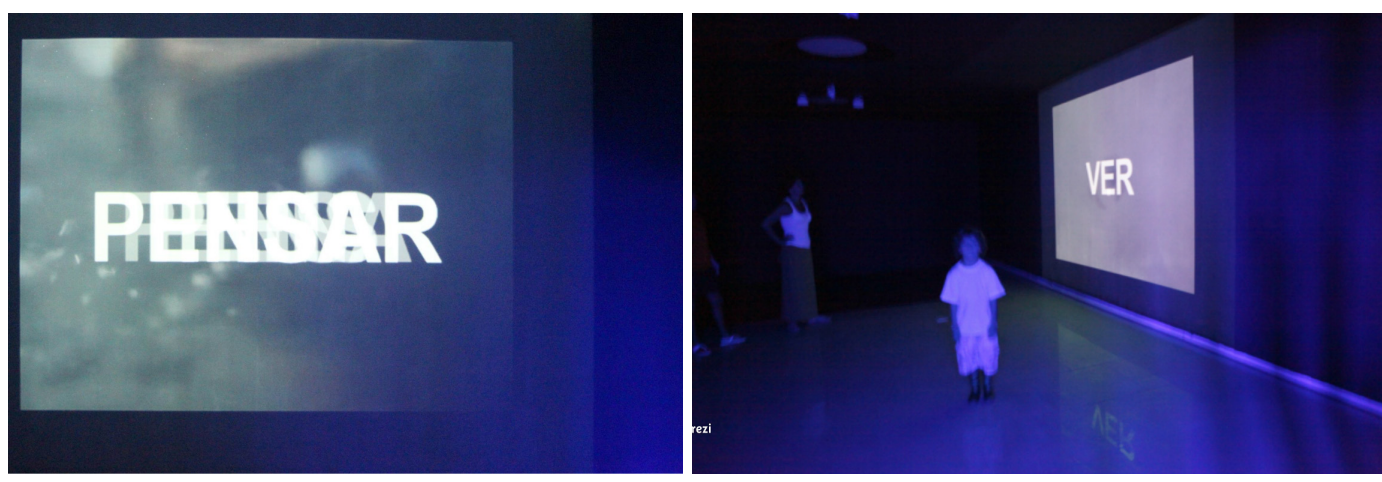

Figuras 1 e 2: Coisa vista - operações aditivas. Conceito e direção: Lucas Bambozzi.

Desenvolvimento tecnológico: Equipe Amarela (Matheus Knelsen, Lina Lopes, Paloma Oliveira, Caio Bonvenuto). Assistência e desenho sonoro: Caio Bonvenuto Fonte: Bambozzi, (s. d.).

http://www.lucasbambozzi.net/archives/1389

A tentativa de estar entre a produção e a teorização procura dar conta da crítica à qual a obra de arte estaria alheia ou aberta. A escolha de utilizar suas obras e exemplos para o debate que fazemos se deu por assumirem a proposta de, pela arte, criarem sobre os processos comunicativos e se colocarem também no lugar de pensadores das questões que promovem. Assim, para além da ação 
artística, se colocam como guardiões de certo debate, na posição de críticos de si mesmos. A arte é sempre crítica? - poderíamos perguntar. Ela se propõe a tentar trabalhar por diferenças poéticas; no entanto, estas não são sempre críticas e às vezes representam simplesmente diferenças. Pensar sobre a própria obra resulta sempre em criticidade? - poderíamos perguntar. Muitas vezes pode ser uma maneira de simplesmente estabelecer novos recobrimentos sobre as diferenças criadas nas obras, mas não exatamente apresentar conteúdo crítico.

Assumimos que o lugar da arte está em disputa, assim como o da crítica e o da crítica de arte. Isso nos permite retirar o peso de imputar qualidade a toda obra e deslocar para um contexto que hoje é de circulação dos trabalhos a possibilidade da crítica. Podemos dizer como posição consensual que toda a obra de arte produz um deslocamento de sentido. Uma segunda característica delas que também podemos considerar dessa forma é sua disposição para o desvio ou deslocamento dos objetos dispostos ou representados. Não podemos, associar todas as vezes esse deslocamento a uma disruptura ou ainda a uma que seja crítica. Dizemos que as obras consideradas no âmbito da web arte têm uma predileção para o deslocamento funcional em relação aos fluxos de comunicação midiática, retirando desse fluxo os elementos básicos de sua composição ou ainda sendo ela mesma inserida no circuito comunicacional. Consideramos que ela seja limítrofe nesse âmbito, podendo muitas vezes ser questionada no seu papel de objeto de arte. Nosso principal propósito, então, ao abordá-la é conseguir defender a possibilidade de uma crítica de mídia por intermédio dos recursos adotados por ela.

Tomamos como base especialmente os trabalhos artísticos e teóricos de Lucas Bambozzi e Fábio Fon não só a partir do que eles apresentam, mas também na tentativa de posicionamento crítico de suas próprias figuras assumindo as perspectivas curatorial, realizadora e analista. Destacamos que o lugar da crítica não está nos realizadores, nos analistas e nem em suas obras, mas nos questionamentos que levantam (discursivamente, culturalmente e no cruzamento entre camadas de mediação). Aqui cabe a pergunta geral: qual é o lugar da crítica? Assim, podemos nos perguntar sobre qual é sua posição no cruzamento 
do uso dos meios digitais, da produção e crítica de arte e da arte incorporada da mídia e mídia incorporada de arte como temos hoje. Nossa hipótese é de que ela não está situada sobre os realizadores, nem nos analistas e críticos e nem nas obras em si, mas no duelo de sentido feito coletivamente sobre o que essas obras provocam (buscando tê-lo provocado por anúncio de seus autores ou por como caem na rede).
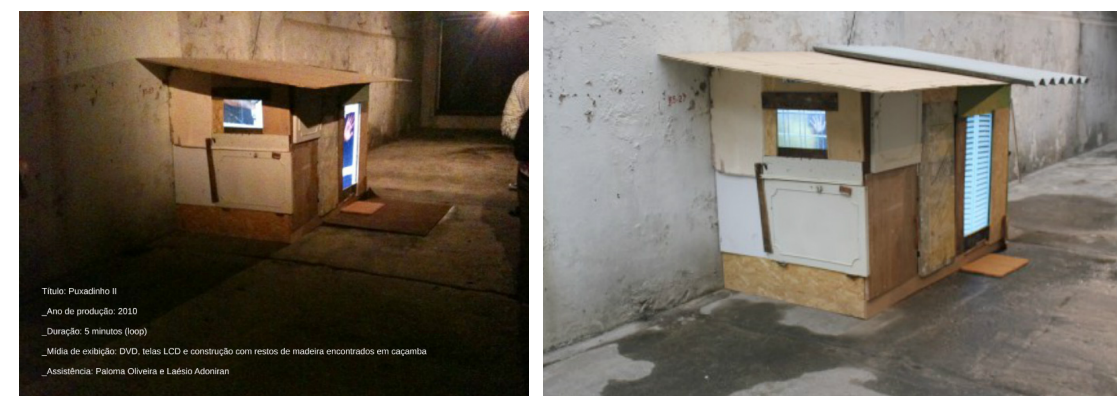

Figuras 3 e 4: Construção com restos de madeira encontrados em caçamba presentes em Puxadinho II Fonte: Puxadinho II (2010).

\section{A memória, o verdadeiro e a visibilidade}

Os meios digitais podem ser criticados a partir da aproximação com o debate sobre três aspectos: a memória, o verdadeiro e a visibilidade. Apontamos inicialmente a questão da relação entre memória e crítica. As obras propõem um debate acerca do trabalho com a memória na acepção de que pode haver uma descontextualização temporal do acesso aos objetos midiáticos não ligados ao mesmo momento da produção ou veiculação em massa. Os meios digitais favorecem a recuperação das memórias no objeto e das memórias de objeto: no primeiro caso apresentando a possibilidade de preservar registros históricos e imemoriais considerados relevantes e, no segundo, valorizando a história que cada um dos objetos usados para acessar memórias conta sobre os tempos de sua utilização e decaída tecnológica. Esse movimento acaba por ser associado e confundido nos trabalhos de web arte com a própria dinâmica da memória. "A memória não é unívoca e os múltiplos caminhos narrativos dessa ficção se 
oferecem a nós como uma maneira de capturar a autêntica multiplicidade da memória" (BOLTER, 2001, p. 127, tradução nossa)³. Se por um lado há extensiva argumentação em relação aos meios digitais e à preservação da memória, há um debate também sobre a possibilidade de esquecimento nos meios digitais com o apagamento de registros de dados e a omissão de informações de questionável relevância pública e privada. Ao mesmo tempo em que se registra, se quer apagar. Assim, podemos dizer que o tempo da crítica também está associado ao tempo da memória e ele se faz muitas vezes descontextualizado em relação aos objetos digitais, reforçando que há uma relação próxima da crítica com o tempo presente.

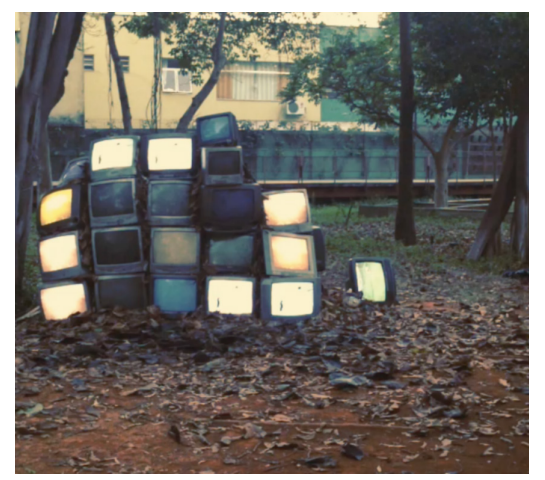

Figura 5: Curto circuito [Último suspiro], instalação realizada na praça Victor Civita Fonte: Bambozzi (2014).

Também é efeito das obras a busca por autenticação e fidedignidade daquilo que se apresenta, desafiando o lugar do verdadeiro em relação à crítica. Há uma possibilidade de remixagem, de retratação dos objetos digitais, de desconfiança sobre sua inteireza e a fragmentação de suas partes. A crítica preocupa-se em trabalhar sobre o que é, o que está dado de comum acordo, ou desenha o que é possível acerca aquele objeto. Desse modo, escapa-se ao objeto da crítica no ponto em que ele perde consenso e circulação massiva; pode-se de alguma forma recuperá-lo de duas maneiras: por justaposição de 
objetos e criação de efeitos para fora da publicação nas redes ou pela criação de objetos de circulação viral que chegam a ser polêmicos nos âmbitos fora do digital. "Mais 'realistas', os que hoje experimentam com os novos meios de difusão, procuram menos esse grande público, quase mítico e sonhado, por um público que tenha mais afinidades com suas ideias e propostas" (PRADO, 2002, p. 116). A medida do verdadeiro pode se dar a partir de um público que endossa de maneira testemunhal e atesta primeiramente a existência da obra e, em segundo lugar, seu lugar como arte. No entremeio dessa possibilidade de verificação encontra-se, dentro da web arte, uma possibilidade de jogar com a relação entre o que parecer ser e o que é, entre o registro de dados e o ficcional, entre o que, enfim, só esteticamente pode ser atestado e verificado em categorias artísticas e de produção midiática. Assim, a arte digital se preocupa em assumir um aspecto de seus equivalentes não-artísticos, gerando uma ambiguidade entre o verdadeiro e o falso (NUNES, 2009a).

Por fim, a crítica incide no diálogo público e, dessa maneira, contamos com a possível visibilidade de seus objetos, marcando a relação entre esta e a crítica. No caso do digital, pode tratar-se de uma visibilidade que parece acessível, brilhante e luminosa nas telas das redes, mas que chega opaca, interferida, matizada nos diálogos fora delas. Se a crítica faz ver elementos interpretativos privilegiados, a arte digital valoriza esses elementos conferindo-Ihes destaque, recorte e repetição. Ao mesmo tempo, é crítico o movimento de todas as produções e dos elementos contidos nelas que não encontram de alguma forma fortuna crítica. Paradoxalmente situam-se num âmbito iluminado das redes digitais, mas apagados de outro circuito de circulação, que é o da produção de sentido nesses meios, habitando espaços de exposição potencialmente visíveis, mas efetivamente obscurecidos, que podemos entender como espaços artísticotecnológicos irreais. Em obras determinadas, pode até existir catalisação de um espaço físico entendido como real. "Também é possível usar a Internet e outras redes telemáticas para criar um vínculo direto com um espaço físico real" (KAC, p. 111). 


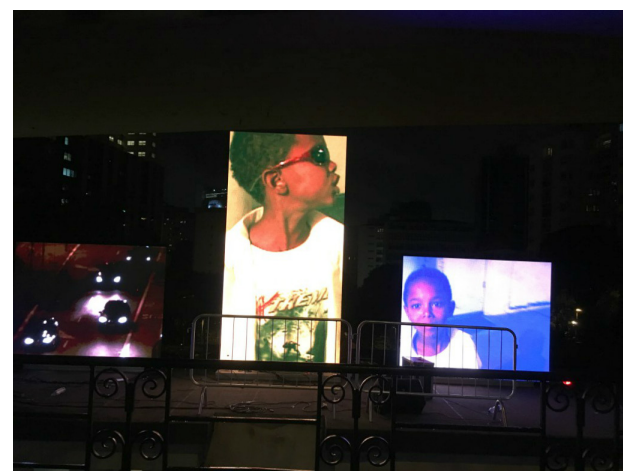

Figura 6: Cena do documentário Museu dos [Corpos] Invisíveis, de Lucas Bambozzi e Gisele Beiguelman. Câmera e edição: Lucas Bambozzi e Lucas Gervilla.

Fonte: http://www.desvirtual.com/museu-dos-corpos-invisiveis/

\section{Crítica privilegiada com os meios digitais}

Nosso objetivo não é avaliar a potência crítica das experiências artísticas aqui relatadas, mas captar aquilo que, ao se anunciar no lugar da experimentação midiática, abre um espaço de cisão e permite identificar o que culturalmente poderia ser objeto da crítica. Num primeiro nível, há questionamento da materialidade dos meios, o esmaecimento da dualidade entre o verdadeiro e o falso, além de um trabalho entre visibilidades e invisibilidades.

o reposicionamento do estudo dos gêneros não se limita a uma mera reflexão acadêmica. Na verdade, constitui um inquérito sobre os mecanismos mobilizadores da cultura em suas diferentes gestões culturas que suportam hoje esse híbrido que é a cultura não só de meios, mas de múltiplas mediações (MACHADO, 2002, p. 71).

Não há problema em afirmar que o digital em si não existe enquanto ordem isolada de outras produções artísticas e midiáticas. Ao nomear tais investidas a partir de um termo que favorece a referência ao suporte, obscurecemos outras categorizações, inclusive genéricas, que elas poderiam receber. Mas apostamos que o processo de criação digital enseja problemas de crítica diferenciados e específicos que merecem ser tratados, como a presença de uma aproximação entre as linguagens do jornalismo, do entretenimento e da arte e a circulação 
diferenciada e mediatizada de suas produções. Ainda que variadas na hibridação entre discursos referenciais e ficcionais que marcam mais uma ou outra produção, elas são similares na forma de acesso, na linguagem, na forma de apresentar-se dentro do eixo do que pode ser lembrado, do verdadeiro, do que se torna visível pelo reconhecimento.

Há uma crítica involuntária, desse modo, pretensamente sem pensamento, acontecida a partir de sucessivas ações de diferentes autores-usuários e apropriações. Podemos chamar de crítica o retrabalho e a apropriação a partir, principalmente, do processo de justaposição de elementos herdado das vanguardas artísticas? Perguntamos em qual lugar se faz essa crítica e quem é seu autor? A crítica seria o processo de mutabilidade das linguagens e dos formatos, no qual acontece a história dessas mudanças? Nossa preocupação tem em mente o que é dito sobre o digital, as pretensas potencialidades e o que ele privilegia. Não estamos no âmbito dos artistas, nem dos analistas e nem dos questionamentos explícitos assumidos pelas obras, mas num ambiente de movimentação dos formatos e linguagens que os retira do uso comum.

Afirmamos que há um privilégio da usabilidade formal e da mutabilidade dos formatos. O princípio da usabilidade aproxima a arte do uso e liga a todos na posição de produzir em vez de retirar criticidade; há investimento em uso crítico por desvio, por apropriação multíplice. Essa é uma aposta, mas a limitação ao uso ainda é um impedimento. Ao mesmo tempo, a lógica da visibilidade da mudança de formatos é privilegiada.

Para além das tendências mais confortáveis da tecnofilia e da tecnofobia, o que importa é politizar o debate sobre as tecnologias, sobre as relações entre a ciência e o capital, sobre o significado se se criarem obras artísticas com pesada mediação tecnológica (MACHADO, 2007, p. 38).

Nossa aposta final é a de que há um tipo de movimento crítico que se soma à variação dos formatos e que isso se faz mais visivelmente com as possibilidades de uso das mídias digitais. Entendemos que - na maior aproximação entre as linguagens do jornalismo, dos meios direcionados ao entretenimento e da arte 
alegada e que se revela tanto no conteúdo quanto na forma do que é apresentado - há adesão e apropriação por parte do público usuário das obras. Propomos que esse ambiente favoreça um tipo específico de crítica por multitude, resultante de um processo de apropriação não autoral a partir da usabilidade formal e mutabilidade dos formatos.

Os alunos chegam a um resultado, um produto final, entretanto 0 conhecimento produzido encontra-se na processualidade, nas maneiras em que se experimentam realizando o trabalho, nas posturas de enfrentar os desafios, nas concepções do pensamento construindo realidades, e até nos desejos produzidos (OLIVEIRA; FONSECA; BIAZUS, 2007).

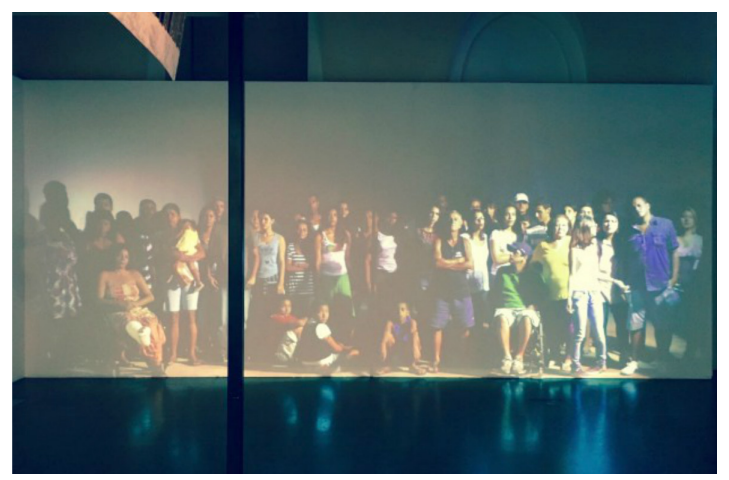

Figura 7: Welt Kompakt - 20 de agosto de 2017 - Q21. Filmagem participativa como parte do projeto Multitude

\section{Referências}

AUMONT, J.; MARIE, M. Dicionário teórico e crítico de cinema. Campinas: Papirus, 2003.

BAMBOZZI, Lucas. Curto circuito [último suspiro]. 2014. Instalação, 30 televisores. . Lucas Bambozzi. [S. I], [s. d.]. Disponível em: <https://bit.ly/2qQOQ4P>. Acesso em: 23 abr. 2018. 
BEIGUELMAN, G. Link-se: arte/mídia/política/cibercultura. São Paulo: Peirópolis, 2005.

BENJAMIN, W. A obra de arte na era da sua reprodutibilidade técnica. In: . Textos escolhidos. São Paulo: Ed. Abril, 1975. (Série Os Pensadores).

p. $10-34$.

BLANCO, B. ; HILDEBRAND, H. R.; MORONI, A. M. F. S. Interatividade e multissemiose na web arte brasileira. In: ENCONTRO NACIONAL DE HISTÓRIA DA MÍDIA, 10., Porto Alegre, 2015. Anais... Porto Alegre: Alcar, 2015. Disponível em: <https:// bit.ly/2vpIzlt>. Acesso em: 18 abr. 2018.

BOLTER, J. D. Writing space: computers, hypertext, and the remediation of print. New York: Routledge, 2001.

BOURRIAUD, N. Estética relacional. Buenos Aires: Adriana Hidalgo Editora, 2006.

. Pós-produção. São Paulo: Martins Fontes, 2009.

BULHÕES, M. A. Web arte: a e-imagem e seus contextos de representação. In: PARODE, F. P.; SALVATORI, M.; SILVA, A. R. (Orgs.). Imagem e tecnologias da representação. São Paulo: Entremeios, 2011a. p. 33-50.

Web arte e poéticas do território. Porto Alegre: Zouk, 2011b.

FREITAS, S.; PEREIRA, M. F. Cinema expandido e espaço acústico: fundamentos teóricos da construção do conceito de crítica expandida na web. In: CONGRESSO BRASILEIRO DE CIÊNCIAS DA COMUNICAÇÃO, 36., Manaus, 2013. Anais... Manaus: Intercom, 2013. 
GIANNETTI, C. (Ed.). Ars telemática: telecomunicación, internet y ciberespacio. Barcelona: L'Angelot, 1998.

KAC, E. Novos rumos na arte interativa. In: LEÃO, L. (Org.) Interlab: labirintos do pensamento contemporâneo. São Paulo: Iluminuras; Fapesp, 2002. p. 107-115.

LEENHARDT, J. Crítica de arte e cultura no mundo contemporâneo. In: MARTINS, M. H. (Org.). Rumos da crítica. 2. ed. São Paulo: Senac; Itaú Cultural, 2007. p. 19-28.

MACHADO, A. Arte e mídia. Rio de Janeiro: Jorge Zahar, 2007.

MACHADO, I. Gêneros no contexto digital. In: LEÃO, L. (Org.). Interlab: labirintos do pensamento contemporâneo. São Paulo: Iluminuras; Fapesp, 2002. p. 71-82.

MATTES, Eva; MATTES, Franco. 0100101110101101.ORG. Disponível em: <https:// bit.ly/1GHEhS7>. Acesso em: 12 fev. 2012.

NUNES, F. O. Web arte no Brasil: algumas poéticas e interfaces no universo da rede internet. 2003. 113 f. Dissertação (Mestrado em Multimeios) - Instituto de Artes, Universidade Estadual de Campinas, Campinas, 2003. Disponível em: <https://bit.ly/2J5WMpz>. Acesso em: 22 abr. 2008.

. CTRL+ART+DEL: pressupostos reflexivos para pequenos distúrbios em arte e tecnologia. In: ENCONTRO DA ASSOCIAÇÃO NACIONAL DE PESQUISADORES EM ARTES PLÁSTICAS, 18., Salvador, 2009. Anais... Salvador: Edufba, 2009a. p. 426-438. Disponível em: <https://bit.ly/2EU0Y9D>. Acesso em: 5 ago. 2014.

Captas. FON - Fabio Oliveira Nunes. [S. I.], 22 nov. 2009b. Disponível em: <https://bit.ly/2F6MvqV>. Acesso em: 5 ago. 2014. 
$C T R L+A R T+D E L$ : distúrbios em arte e tecnologia. São Paulo: Perspectiva, 2010a.

NUNES, F. O. Reflexões sobre web arte em novos contextos. Porto Arte, Porto Alegre, v. 17, n. 28, p. 85-98, 2010b.

NUNES, F. O. ; BRAZ, S. Intromissão e invisibilidade em experimentações artísticas com radiação eletromagnética. Visualidades, Goiânia, v. 8, n. 1, p. 160-173, 2010. Disponível em: <https://bit.ly/2HcxrK0>. Acesso em: 18 abr. 2018.

PRADO, G. Experimentações artísticas em redes telemáticas e web. In: LEÃO, L. (Org.). Interlab: labirintos do pensamento contemporâneo. São Paulo: Iluminuras; Fapesp, 2002. p. 115-124.

- Arte telemática: dos intercâmbios pontuais aos ambientes virtuais multiusuário. São Paulo: Itaú Cultural, 2003.

PUXADINHO II. Assistência de Paloma Oliveira e Laésio Adoniran. Local: Produtora, 2010. 1 DVD (5 min em loop).

SHUSTERMAN, R. Vivendo a arte: o pensamento pragmatista e a estética popular. Tradução Gisela Domschke. São Paulo: Editora 34, 1998.

SILVA, G. ; SOARES, R. L. Para pensar a crítica de mídias. Famecos, Porto Alegre, v. 20, n. 3, p. 820-839, 2013. Disponível em: <https://bit.ly/2IZoi8f>. Acesso em: 17 abr. 2018.

SOARES, R. L.; SILVA, G. Lugares da crítica na cultura midiática. Revista Comunicação, Mídia e Consumo, São Paulo, v. 13, n. 37, p. 9-28, maio/ago. 2016. 
SODRÉ, M. Eticidade, campo comunicacional e midiatização. In: MORAES, D. (Org.). Sociedade midiatizada. Rio de Janeiro: Mauad, 2006. p. 19-31.

YOUTAG, 2008. Lucas Bambozzi, [S.I.], [2008]. Disponível em: <https://bit. ly/2qKI6pt>. Acesso em: 8 abr. 2015.

submetido em: 07 abr. 2018 | aprovado em: 29 abr. 2018 